\title{
Allopurinol and glutamine attenuate bacterial translocation in chronic portal hypertensive and common bile duct ligated growing rats
}

\author{
G Schimpl, P Pesendorfer, G Steinwender, G Feierl, M Ratschek, M E Höllwarth
}

\begin{abstract}
Background-Spontaneous bacterial infections and septicaemia result in morbidity and mortality in patients with portal hypertension and obstructive jaundice.

Aim-The aim of this study in rats was to investigate the incidence of bacterial translocation in portal hypertension and obstructive jaundice, and to evaluate the effects of allopurinol and glutamine.

Methods-Rats were subjected to sham laparotomy (SL), portal hypertension (PH) by calibrated stenosis of the portal vein, and common bile duct ligation (CBDL). Animals of each group were either treated with allopurinol $(50 \mathrm{mg} / \mathrm{kg}$ twice a week), glutamine (1 g/kg/d), and allopurinol and glutamine.

Results-After four weeks, significant bacterial translocation in the untreated PH and CBDL rats occurred. Intestinal mucosal malondialdehyde concentrations (MDA), as an indicator for lipid peroxidation, and myeloperoxidase activity (MPO) released from activated neutrophils were also significantly increased $(p<0 \cdot 01)$. Allopurinol and glutamine in $\mathrm{PH}$ and CBDL rats improved bacterial translocation, and decreased MDA and MPO values $(\mathbf{p}<0.01)$.

Conclusion-In PH and CBDL rats significant bacterial translocation, ileal mucosal lipid peroxidation, and neutrophil derived MPO activity occurred. Allopurinol and glutamine significantly reduced bacterial translocation, as well as ileal mucosal MDA and MPO activities. (Gut 1996; 39: 48-53)
\end{abstract}

Keywords: bacterial translocation, portal hypertension, obstructive jaundice, lipid peroxidation, allopurinol, glutamine.

Spontaneous bacterial infections and sepsis resulting in morbidity and mortality have been reported in patients with chronic portal hypertension (PH) and obstructive jaundice. ${ }^{12}$ Most of these infectious episodes are spontaneous without apparent sources of infection, and caused by aerobic bacteria normally present in the intestine. ${ }^{3}$ Chronic $\mathrm{PH}$ and obstructive jaundice disrupt the intestinal barrier by producing structural changes in the bowel mucosa, ${ }^{45}$ inducing the formation of portal systemic shunts, bacterial overgrowth, by the absence of intestinal bile flow, malnutrition, decreased bacterial clearance by the reticuloendothelial system, and impaired immunological defence. ${ }^{6-10}$

$\mathrm{PH}$, either isolated or as a sequence of hepatic diseases leads despite an hyperdynamic splanchnic flow state to intestinal mucosal hypoxaemia by arterial hypoperfusion. ${ }^{11}$ Decreased intestinal arterial perfusion results in an increased conversion of xanthine dehydrogenase to xanthine oxidase, with subsequent lipid peroxidation. ${ }^{12}$ The intestinal mucosa is one of the richest sources of xanthine oxidase. ${ }^{13}$ This initiates an oxidative damage of intestinal mucosal cells and leads to intestinal mucosal atrophy. ${ }^{11} 13$ In this compromised bowel mucosa polymorphonuclear (PMN) neutrophil accumulation occurs triggered by oxygen metabolites and destructive toxins from these cells are released and further damage the intestinal mucosa. ${ }^{14} 15$

The aim of this study was to estimate intestinal mucosal malondialdehyde (MDA) and myeloperoxidase concentrations (MPO) in chronic $\mathrm{PH}$ and common bile duct ligation (CBDL) and to investigate the effects of allopurinol and glutamine on intestinal mucosal lipid peroxidation and PMN neutrophil derived MPO activity on bacterial translocation in chronic $\mathrm{PH}$ and $\mathrm{CBDL}$ growing rats.

Allopurinol, a competitive xanthine oxidase inhibitor, acts as a free radical scavenger and prevents lipid peroxidation. ${ }^{16}$ The amino acid glutamine has received considerable attention in the past, because of new knowledge showing that glutamine is required for mucosal growth and bolsters intestinal barrier function. ${ }^{17}$

\section{Methods}

Male, 4 weeks old, Sprague-Dawley rats $(150 \mathrm{~g}$ to $170 \mathrm{~g}$ ) were used for all experiments. All animals were housed in a controlled environment and permitted free access to food and water. All experiments were approved by the animal research commission of the ministry of science and conformed to guidelines for the care and use of laboratory animals.

Animals were randomly assigned to one of the three groups: sham laparotomy (SL, $n=40), P H(n=40)$, and CBDL $(n=40)$. The rats were anaesthetised with ketamine (100 $\mathrm{mg} / \mathrm{kg}$ intraperitoneally) and under aseptic conditions a midline laparotomy was performed. In the SL group the common bile duct and the portal vein were dissected free and the abdomen was closed. PH was produced by calibrated stenosis of the portal vein. A 21 gauge blunt tipped needle was placed alongside the vein and both vein and needle were 
ligated with 4-0 silk ligature. The needle was removed, leaving a 21 gauge stenosis in the portal vein.

Obstructive jaundice was produced by ligation of the common bile duct with a 3-0 silk ligature. The abdomen was closed in two layers with absorbable sutures, and the animals were permitted four weeks recovery with free access to food and water.

\section{Treatment}

The three groups SL, PH, and CBDL, were subdivided into four subgroups: (a) 10 animals served as controls; (b) 10 rats received allopurinol (50 mg/kg intraperitoneally) twice a week; (c) in 10 rats glutamine was given ( $1 \mathrm{~g} / \mathrm{kg} / \mathrm{d}$ orally); (d) 10 rats were treated with allopurinol and glutamine (allopurinol $50 \mathrm{mg} / \mathrm{kg}$ twice a week intraperitoneally and glutamine $(1 \mathrm{~g} / \mathrm{kg} / \mathrm{d}$ orally).

\section{Experimental design}

After four weeks the animals were weighed, and under ketamine anaesthesia and sterile conditions a midline laparotomy was made. The exposed viscera were swabbed with a sterile cotton tipped applicator stick, which was immediately placed on blood agar plates. Portal pressure was measured after cannulating the superior mesenteric vein with a 21 gauge needle connected to a manometer, and the height of the right atrium was taken as zero reference level. Blood samples were withdrawn from the vena cava for the measurement of serum liver enzymes (total bilirubin, aspartate aminotransferase (AST), alanine aminotransferase (ALT), alkaline phosphatase (AP), cholinesterase (CHE), and total serum protein.

Aliquots of portal vein blood and vena cava blood $(0.1 \mathrm{ml})$ were plated onto blood agar plates. The central mesenteric lymph node complex (MLN), the spleen, and the liver were harvested with new sterile instruments and weighed. A $1.5 \mathrm{~cm}$ long sample of the terminal ileum was excised, opened on its antimesenteric border, and washed in sterile $0.9 \%$ saline solution. The MLN complex, parts of the liver and spleen were cut off, weighed, placed in grinding tubes containing sterile brain-heart infusion 1:9, and homogenised. Serial dilutions of the homogenates were made and $0.1 \mathrm{ml}$ of each dilution was plated on blood, endo, and MRS agar plates and incubated aerobically for 48 hours at $37^{\circ} \mathrm{C}$. The plates were evaluated for bacterial growth by standard bacteriological technique. Any growth in the plates was considered positive and expressed as colony forming unit per gram tissue (cfu/g).

For determination of MDA and MPO ileal mucosa was scrubbed off and weighed. All specimens were immediately frozen in liquid nitrogen until assay. MDA was determined as an index of ileal mucosal lipid peroxidation according to the method of Wong et al. ${ }^{18} \mathrm{MPO}$ was assayed as an indicator for activated PMN neutrophils using the method of Krawisz et al. ${ }^{19} \mathrm{MDA}$ values were expressed as $\mathrm{nmol} / \mathrm{g}$ dry weight of ileal mucosa, and MPO activity was expressed as U/g dry ileal mucosa. Dry weight of ileal mucosa was estimated after incubation of ileal mucosa at $50^{\circ} \mathrm{C}$ for 48 hours.

Samples of the jejunum, ileum, and liver were taken for histological examination, fixed in buffered formalin, embedded in paraffin wax, cut in 2-3 $\mu \mathrm{m}$ serial sections, and stained with haematoxylin and eosin. Specimens of the liver were also stained with chrom-anilinblue.

The results were expressed as mean (SEM). Statistical analyses between the means of two groups were performed by the Mann-Whitney $\mathrm{U}$ test, and analysis of variance (ANOVA) was used when comparing more than two groups. A p value $<0.05$ or less was considered statistically significant.

\section{Results}

After four weeks, all PH animals showed a patent but stenotic portal vein with dilated mesenteric vessels. All CBDL animals became visibly jaundiced and had a cystic common bile duct remnant proximal to the ligature.

Body weight in all SL rats increased from $160(4 \cdot 8) \mathrm{g}$ to $355(3.2) \mathrm{g}$, and in all PH rats from $155(3 \cdot 2) \mathrm{g}$ to $340(6 \cdot 4) \mathrm{g}$. In all CBDL groups malnutrition with decreased weight gain from $165(3.2) \mathrm{g}$ to $305(4.8) \mathrm{g}$ was present $(\mathrm{p}<0.05)$. Portal pressure $(\mathrm{mm} \mathrm{Hg})$ increased significantly $(\mathrm{p}<0.01)$ in all $\mathrm{PH}$ and CBDL rats without any differences between the subgroups (Table I). Serum liver enzymes remained normal in all SL and PH rats. CBDL resulted in deterioration of liver function, but in the CBDL groups treated with allopurinol and allopurinol/glutamine significant lower concentrations of bilirubin and AST compared with the other CBDL groups were found $(\mathrm{p}<0.01)$.

TABLE I Serum liver enzymes and portal pressure after sham laparotomy (SL), portal hypertension (PH), and common bile duct ligation $(C B D L)$

\begin{tabular}{|c|c|c|c|c|c|c|c|c|c|}
\hline & $S L$ & $P H$ & $\begin{array}{l}\text { PH } \\
+ \text { Allo }\end{array}$ & $\begin{array}{l}P H \\
+G l u\end{array}$ & $\begin{array}{l}\text { PH } \\
+ \text { Allo/Glu }\end{array}$ & $C B D L$ & $\begin{array}{l}\text { CBDL } \\
+ \text { Allo }\end{array}$ & $\begin{array}{l}C B D L \\
+G l u\end{array}$ & $\begin{array}{l}\text { CBDL } \\
+ \text { Allo/Glu }\end{array}$ \\
\hline $\begin{array}{l}\text { Bilirubin }(\mu \mathrm{mol} / \mathrm{l}) \\
\text { AST (U/1) } \\
\text { ALT (U/I) } \\
\text { AP (U/l) } \\
\text { CHE (U/l) }\end{array}$ & $\begin{array}{c}4 \cdot 2(0 \cdot 5) \\
43(5) \\
27(4) \\
231(11) \\
331(19)\end{array}$ & $\begin{array}{c}3 \cdot 9(0 \cdot 6) \\
47(4) \\
37(6) \\
267(10) \\
271(13)\end{array}$ & $\begin{array}{c}3 \cdot 7(0 \cdot 8) \\
51(3) \\
31(3) \\
273(12) \\
271(13)\end{array}$ & $\begin{array}{c}3 \cdot 9(0 \cdot 1) \\
42(6) \\
29(5) \\
254(9) \\
306(10)\end{array}$ & $\begin{array}{c}4 \cdot 3(0 \cdot 5) \\
55(4) \\
34(4) \\
243(11) \\
295(12)\end{array}$ & $\begin{array}{l}136 \cdot 8(5)^{\star} \\
567(37)^{\star} \\
101\left(10^{\star}\right. \\
638(19)^{\star} \\
148(9)^{\star}\end{array}$ & $\begin{array}{l}72 \cdot 7(6)^{\star} \dagger \\
101(18)^{\star} \dagger \\
105(6)^{\star} \\
683(37)^{\star} \\
164(9)^{\star}\end{array}$ & $\begin{array}{l}141 \cdot 9(3)^{\star} \\
+241(9)^{\star} \dagger \\
114(5)^{\star} \\
643(29)^{\star} \\
141(5)^{\star}\end{array}$ & $\begin{array}{l}63 \cdot 3(5)^{\star} \dagger \\
173(9)^{\star} \\
94(4)^{\star} \\
656(31)^{\star} \\
173(11)^{\star}\end{array}$ \\
\hline $\begin{array}{l}\text { Portal pressure } \\
(\mathrm{mm} \mathrm{Hg})\end{array}$ & $7 \cdot 6(2.9)$ & $19 \cdot 2(0 \cdot 4)^{\star}$ & $19 \cdot 6(0 \cdot 3)^{x}$ & ${ }^{\star} 18.9(0.5)^{\star}$ & ^ $19 \cdot 3(0 \cdot 7)^{\star}$ & $20 \cdot 5(0 \cdot 6)^{\star}$ & $18 \cdot 9 \cdot 0 \cdot 6)^{\star}$ & ^ $19 \cdot 3(0 \cdot 9)^{\star}$ & $19 \cdot 1(0 \cdot 5)^{\star}$ \\
\hline
\end{tabular}

${ }^{\star} \mathrm{p}<0.01 v \mathrm{SL} ; \mathrm{tp}<0.01$ control group $v$ allopurinol (Allo), glutamine (Glu), and allopurinol/glutamine (Allo/Glu) treated groups. Data shown as mean (SEM). 
TABLE II Incidence of bacterial translocation after $S L, P H$, and $C B D L$

\begin{tabular}{lllllll}
\hline & Peritoneum & Portal vein & Vena cava & Liver & Spleen & $M L N$ \\
\hline SL & ND & ND & ND & ND & $1 / 10$ & $4 / 10$ \\
SL+Allo & ND & ND & ND & ND & $2 / 10$ & $3 / 10$ \\
SL+Glu & ND & ND & ND & ND & $1 / 10$ & $3 / 10$ \\
SL+Allo/Glu & ND & ND & ND & ND & $2 / 10$ & $4 / 10$ \\
PH & 1/10 & 3/10 & 1/10 & $4 / 10$ & $2 / 10$ & $5 / 10^{\star}$ \\
PH+Allo & ND & ND & ND & $4 / 10$ & $2 / 10$ & $7 / 10$ \\
PH+Glu & ND & ND & ND & ND & $2 / 10$ & $4 / 10$ \\
PH+Allo/Glu & ND & ND & ND & ND & ND & $4 / 10$ \\
CBDL & 2/10 & 5/10* & 2/10 & $9 / 10^{\star}$ & $4 / 10$ & $9 / 10^{\star}$ \\
CBDL+Allo & ND & ND & ND & $3 / 10$ & $1 / 10$ & $5 / 10$ \\
CBDL+Glu & ND & ND & ND & $3 / 10$ & $3 / 10$ & $5 / 10$ \\
CBDL+Allo/Glu & ND & ND & ND & $3 / 10$ & $1 / 10$ & $4 / 10$
\end{tabular}

${ }^{\star} \mathrm{p}<0.05$ control groups $v$ Allo, Glu, Allo/Glu groups. Abbreviations as Table I. ND=not detected.

TABLE III Ileal colonisation after $S L, P H$, and $C B D L$

\begin{tabular}{llll}
\hline & $S L$ & $P H$ & $C B D L$ \\
\hline Gram positive & $1.6(0.3) \times 10^{4}$ & $2 \cdot 5(1 \cdot 1) \times 10^{5 \star}$ & $4.9(0.9) \times 10^{5 \star}$ \\
Gram negative & $3.9(0.4) \times 10^{3}$ & $6.3(1.0) \times 10^{3 \star}$ & $3.8(0.7) \times 10^{4 \star}$ \\
\hline
\end{tabular}

${ }^{{ }_{\mathrm{p}}}<0.01 v \mathrm{SL}$. Abbreviations as Table I. Data shown as mean (SEM).

\section{Bacterial translocation and ileal colonisation (Table II)}

After SL, bacterial translocation occurred in $8 \%$ to $10 \%$ of the MLN and spleen without significant differences between the control group and allopurinol, glutamine, and allopurinol/ glutamine treated animals. Translocating bacterias cultured in the spleen and MLN were lactobacilli species in $80 \%$ and Escherchia coli in $20 \%$.

In $\mathrm{PH}$, the incidence of bacterial translocation increased to $23 \%$ in the control group, and bacterial translocation to the peritoneum, vena cava, portal vein, liver, spleen and MLN occurred. Allopurinol and glutamine treatment decreased the rate of bacterial translocation to $10 \%$ and $7 \%(\mathrm{p}<0.05 v$ control). Lactobacilli, streptococci, enterococci species, and $E$ coli were the most commonly cultured bacterias.

CBDL resulted in a bacterial translocation rate of $52 \%$ in the control group. Positive cultures of the peritoneum, vena cava, portal vein, liver, spleen, and MLN were found. Lactobacilli, streptococci, enterococci, and $E$ coli were the main translocating bacterias. Allopurinol and glutamine treatment significantly reduced the incidence of bacterial translocation to $18 \%$ and $13 \%$ in CBDL animals

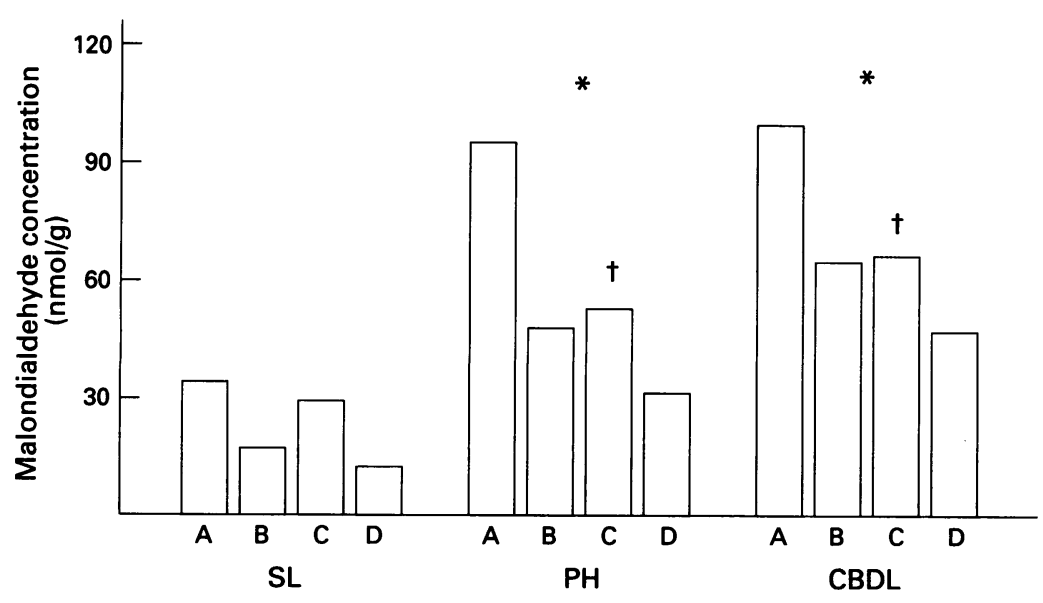

Figure 1: Malondialdehyde values in ileal mucosa ( $S L=$ sham laparotomy, $P H=$ portal hypertension, $C B D L=$ common bile duct ligation). $A=$ control, $B=$ allopurinol,
$C=$ glutamine, $D=$ allopurinol/glutamine. ${ }^{\star} p<0.01$ v $S L ;$ t $<<0.01 A v B, C, D$.
( $\mathrm{p}<0.05 v$ control). The quantitative analysis of bacteria colonising the ileum showed a significant $(p<0.01)$ Gram positive and Gram negative overgrowth in all $\mathrm{PH}$ and $\mathrm{CBDL}$ animals (Table III). This overgrowth was shown by higher cfu/g ileum of Gram positive lactobacilli species, streptococci, and Gram negative $E$ coli, enterococci, and pasteurella strains.

\section{$M D A$ in the ileal mucosa (Fig 1)}

After SL ileal mucosal MDA concentrations were between $31.2(0.3) \mathrm{nmol} / \mathrm{g}$ and $36.6(2 \cdot 1)$ $\mathrm{nmol} / \mathrm{g}$ in the control and glutamine supplemented groups. Treatment with allopurinol and allopurinol/glutamine resulted in significant lower values $(p<0.05)$ of ileal MDA, $19 \cdot 2$ $(2 \cdot 1) \mathrm{nmol} / \mathrm{g}$ and $17 \cdot 1(1 \cdot 3) \mathrm{nmol} / \mathrm{g} \mathrm{respec}-$ tively. PH led to a significant increase of MDA values compared with the SL group $(p<0 \cdot 01)$. Treatment with allopurinol, glutamine, and allopurinol/glutamine significantly attenuated MDA concentrations $(p<0.01)$ compared with the PH control group (control 98.7 (1.6) $\mathrm{nmol} / \mathrm{g}$, allopurinol $49 \cdot 2(1 \cdot 4) \mathrm{nmol} / \mathrm{g}$, glutamine $51.0(3.6) \mathrm{nmol} / \mathrm{g}$, allopurinol/glutamine $32 \cdot 4(2 \cdot 6) \mathrm{nmol} / \mathrm{g})$.

After CBDL, the MDA value in the control group increased to $102.2(1.4) \mathrm{nmol} / \mathrm{g}(\mathrm{p}<0.01$ $v$ SL). In the allopurinol, glutamine, and allopurinol/glutamine treated CBDL animals significantly decreased MDA values $(p<0.01)$ were present (allopurinol $66.1(2 \cdot 4) \mathrm{nmol} / \mathrm{g}$, glutamine $67 \cdot 2(1 \cdot 3) \mathrm{nmol} / \mathrm{g}$, allopurinol/glutamine $52 \cdot 1(2 \cdot 4) \mathrm{nmol} / \mathrm{g})$.

\section{$M P O$ in the ileal mucosa (Fig 2)}

Ileal mucosal MPO activities after SL showed a mean value of $286(4 \cdot 8) \mathrm{U} / \mathrm{g}$ without any significant differences between the subgroups.

$\mathrm{PH}$ resulted in a significant increase $(p<0.01)$ of MPO activity in the control group to 866 (5) U/g. Allopurinol and glutamine treatment significantly decreased MPO activities to a mean of $326(14) \mu / g(p<0 \cdot 01)$.

In the CBDL animals MPO activity increased to $1016(7 \cdot 1) \mathrm{U} / \mathrm{g}$ in the control group. Treatment with allopurinol and glutamine significantly reduced MPO activities to a mean of $369(8) \mathrm{U} / \mathrm{g}(\mathrm{p}<0.01)$.

\section{Histological examination}

Microscopically, the ileum was normal in all $\mathrm{SL}, \mathrm{PH}$, and CBDL rats. In the jejunum, the mucosa showed a mild atrophy with decreased villus height in untreated and allopurinol treated PH and CBDL animals, but these differences were not statistically significant compared with the SL groups and glutamine treated animals. The liver of untreated and glutamine treated rats showed a fibrosis grade III with periportal inflammation and bile duct proliferation (Fig 3). The liver of allopurinol and allopurinol/glutamine treated animals had a lesser degree of fibrosis, classified as grade I-II (Fig 4), and this was statistically significant (p 0.05). 


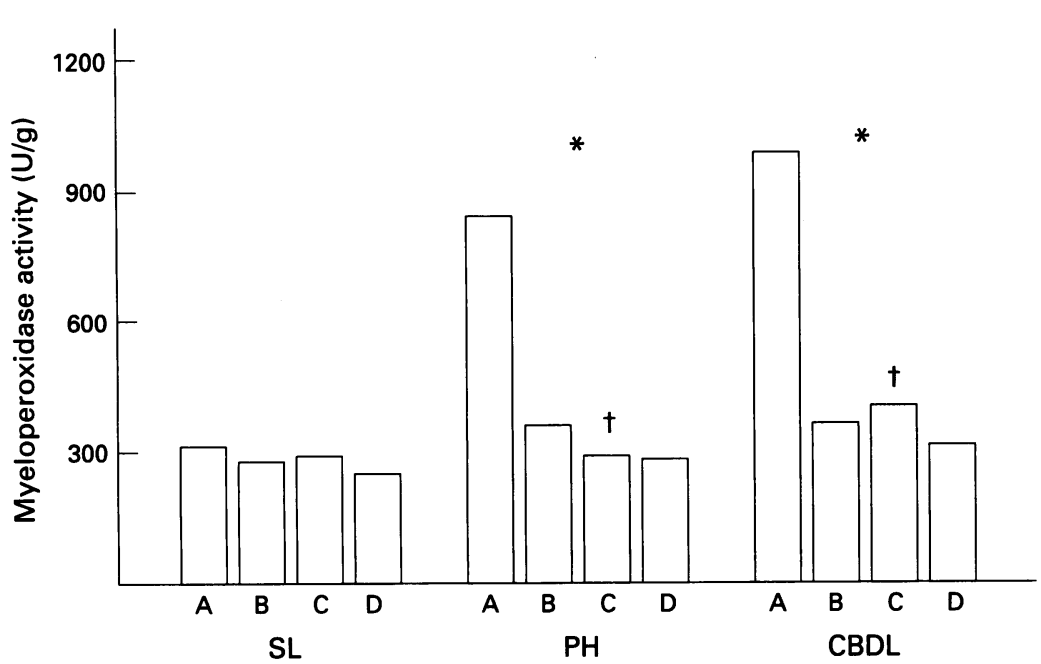

Figure 2: Myeloperoxidase activities in ileal mucosa. $A=$ control, $B=$ allopurinol, $C=$ glutamine, $D=$ allopurinolglutamine. ${ }^{*} p<0.01 v S L ;+p<0.01 A v B, C, D$. Abbreviations as in Figure 1.

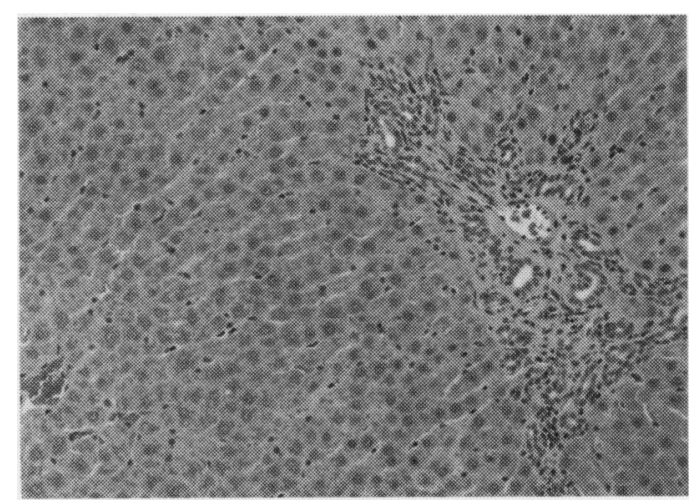

Figure 4: Histological examination of the liver,

haematoxylin and eosin staining, $\times 250$; fibrosis grade $I-I I$ in the allopurinol treated $C B D L$ animals.

increasing intestinal permeability and favouring the transmural passage of bacterias. ${ }^{426}$ Intestinal bacterial overgrowth with destruction of the ecological balance of the normal indigenous microflora is reported in cholestatic diseases. ${ }^{27}$ It is supposed that the absence of intestinal bile acids and $\operatorname{sig} \mathrm{A}$, which have bacteriostatic properties, promote intestinal bacterial overgrowth. ${ }^{28}$ Furthermore, $\mathrm{PH}$ and obstructive jaundice leads to malnutrition, and an association between malnutrition and infectious complications has been reported. ${ }^{29}$ Protein undernutrition disrupts the normal ecology of the gut microflora and leads to intestinal mucosal atrophy. ${ }^{30} 31$ The intestinal mucosa is an extremely active metabolic tissue that exhibits high rates of epithelial replication. It is supposed that protein malnutrition increases enteric bacterial overgrowth, and influences the composition of the intestinal flora. ${ }^{8}$ Chronic obstructive jaundice, the absence of intestinal bile flow, impaired hepatic reticuloendothelial system function, intestinal bacterial overgrowth, and physical disruption of gut mucosal barrier explain the high incidence of infectious complications in this disease..$^{51} \mathrm{PH}$ impairs systemic immunity by shunting the portal blood away from the liver to systemic circulation. ${ }^{3} \mathrm{PH}$ also occurs as a result of hepatic fibrosis with increased vascular resistance by compression of hepatic venules by regenerative nodules. ${ }^{32}$ Lipid peroxidation and the generation of oxygen derived free radicals has also been associated with hepatic fibrogenesis. ${ }^{33}$ In obstructive jaundice high concentrations of lipid peroxides are believed to be an important mediator for liver fibrosis, intestinal bacterial overgrowth, intestinal mucosal atrophy, and neutrophil infiltration into the bowel. ${ }^{1434}$ Increased plasma concentrations of lipid peroxides have been reported in patients with cholestatic diseases. ${ }^{35} 36$ Several studies were undertaken to investigate mechanisms that initiate and favour bacterial translocation in $\mathrm{PH}$ and obstructive jaundice.

$\mathrm{PH}$, either isolated or as a result of liver fibrosis, leads despite an hyperdynamic splanchnic circulatory state, to intestinal mucosal hypoperfusion and hypoxaemia. ${ }^{11}$ Hypoxaemia can initiate an increased conversion of xanthine dehydrogenase to xanthine oxidase (XO) with subsequent formation of
Figure 3: Histological examination of the liver, haematoxylin and eosin staining, $X 250$; fibrosis grade III was present in the control CBDL group. 
oxygen derived free radicals. ${ }^{16}$ The intestinal mucosa is one of the richest sources of XO. In several studies the role of XO induced lipid peroxidation on intestinal permeability and subsequent generation of oxygen derived free radicals triggering bacterial translocation has been elucidated in intestinal ischaemic conditions. ${ }^{12} 14$ 33-35 These oxygen derived free radicals also trigger attractants like activated PMN neutrophils, which have the ability to release a complex of reactive oxygen metabolites that can destroy normal cells and can dissolve connective tissue. ${ }^{37}$ Therefore increased XO values generated by mucosal hypoperfusion change intestinal mucosal membranes by lipid peroxidation, and promote PMN neutrophil infiltration into the bowel initiated by $\mathrm{XO}$ derived free radical metabolites. Both XO and PMN neutrophil accumulation are believed to mediate mucosal damage in themselves, leading to bacterial overgrowth, mucosal atrophy, and increased intestinal permeability. ${ }^{15} 3738$

Allopurinol acts as a free radical scavenger, and the proposed mechanism for its protective effects includes XO inhibition and prevention of toxic oxygen radical formation. ${ }^{39}$ Glutamine has been shown to be the main fuel used by gut mucosal cells as a regulator of cell proliferation and as an essential amino acid for mucosal growth and function. ${ }^{40}$ Glutamine prevents enteric bacterial overgrowth and influences the composition of the intestinal flora, perhaps favouring bacterial species with lack of the characteristics necessary for translocation. ${ }^{41}$

In this study we investigated the role of intestinal mucosal lipid peroxidation and PMN neutrophil derived MPO activity on bacterial translocation in growing rats with $\mathrm{PH}$ and CBDL. Further, we evaluated possible effects of a treatment with allopurinol and glutamine. In growing rats with $\mathrm{PH}$ significant bacterial translocation, increased intestinal mucosal lipid peroxidation, MPO activity, and ileal bacterial overgrowth with Gram negative and Gram positive bacterias occurred. This is in contrast with other studies, where bacterial translocation was only observed in acute $\mathrm{PH}$, or in $\mathrm{PH}$ in association with haemorrhagic shock. ${ }^{438}$ These reported differences in bacterial translocation might be attributed to the fact, that in our study growing rats were analysed after four weeks of $\mathrm{PH}$, whereas in other studies adult rats were investigated after 14 days of $\mathrm{PH}$. A possible explanation for the differences in bacterial translocation between growing and adult rats might be a decreased resistance of the intestinal mucosal barrier against bacterias during maturation of intestinal integrity. ${ }^{42}$ Both allopurinol and glutamine treatment in $\mathrm{PH}$ rats, significantly decreased bacterial translocation, ileal mucosal MDA and MPO values compared with untreated animals.

No differences in ileal and jejunal bacterial colonisation and histomorphology of the jejunum and ileum between untreated and treated $\mathrm{PH}$ rats were present. These findings show that in isolated $\mathrm{PH}$ mucosal lipid peroxidation and MPO activity contribute to increased intestinal permeability for bacterias, which could be prevented by allopurinol and glutamine.

CBDL in growing rats resulted in a significant deterioration of liver function, but with significant lower values of bilirubin and AST in the allopurinol/glutamine treated group.

This might be explained by the fact that liver fibrosis is mediated by lipid peroxides, which can be blocked by allopurinol. ${ }^{43}$ The histological investigation of the liver confirmed this hypothesis, because there was less periportal fibrosis and portal infiltration in the allopurinol/glutamine treated CBDL group compared with the other CBDL animals. In untreated CBDL rats, bacterial translocation occurred in $52 \%$ and this could be increased to $13 \%-18 \%$ by allopurinol and glutamine treatment. Significant ileal bacterial overgrowth with Gram positive and Gram negative bacterias was present in all CBDL rats and this was unaffected by all treatment regimens. In contrast, allopurinol and glutamine significantly decreased ileal mucosal MDA and MPO values indicating a protective effect on mucosal lipid peroxidation and intestinal PMN neutrophil infiltration in CBDL rats. Histomorphologically, the ileum and jejunum did not show important differences between untreated and treated animals with CBDL except a mild mucosal atrophy in the jejunum of untreated and allopurinol treated rats.

In summary, chronic PH and CBDL in growing rats are associated with significant bacterial translocation and ileal bacterial overgrowth with Gram positive and Gram negative aerobes. Significant intestinal mucosal lipid peroxidation and PMN neutrophil derived MPO activity occurred, and this might be an additional important mechanism that disrupts the intestinal mucosal barrier function and increases the egress of gut bacterias to extraintestinal organs.

Allopurinol, a competitive XO inhibitor and free radical scavenger, reduced intestinal mucosal lipid peroxidation by direct inhibition of XO and indirectly decreased intestinal PMN neutrophil derived MPO activity resulting in a considerably lower rate of bacterial translocation in $\mathrm{PH}$ and CBDL. Glutamine supplementation in $\mathrm{PH}$ and CBDL rats had the same inhibitory effect on bacterial translocation, intestinal mucosal lipid peroxidation, and MPO activity. This might be attributed to the fact that glutamine supports intestinal mucosal growth and cell turnover thus bolstering intestinal barrier function, which makes the intestinal mucosa more resistant to bacterial overgrowth and hypoxaemia caused by $\mathrm{PH}$.

The clinical significance of this study in growing rats remains speculative. Our findings suggest, however, that inhibitors of oxygen derived free radicals like allopurinol, and regulators of intestinal mucosal cell proliferation like glutamine might be useful as prophylactic agents to reduce infectious complications in $\mathrm{PH}$ and obstructive jaundice.

Presented in part at the 8th International Symposium on Paediatric Surgical Research, Dublin, 24-25 July 1995. 
1 Gilgert JA, Kamath PS. Spontaneous bacterial peritonitis: an update. Mayo Clin Proc 1995; 70: 365-70.

2 Mihas AA, Toussaint J, Hsue HS, Dotherow P, Achord JL Spontaneous bacterial peritonitis in cirrhosis: clinical and laboratory features, survival and prognostic indicators. Hepatogastroenterology 1992; 39: 520-2.

3 Garcia-Tsao G. Spontaneous bacterial peritonitis. Gastroenterol Clin North Am 1992; 21: 257-75.

4 Garcia-Tsao G, Albillos A, Barden GE, West AB. Bacterial translocation in acute and chronic portal hypertension. Hepatology 1993; 17: 1081-5.

5 Deitch EA, Sitting K, Li M, Berg RD, Specian RD. Obstructive jaundice promotes bacterial translocation from the gut. Am $\mathcal{F}$ Surg 1990; 159: 79-4.

6 Blei AT. Portal hypertension. Current Opinion in Gastroenterology 1994; 10: 295-302.

7 Ding JW, Andersson R, Soltesz V, Willen R, Bengmark S. The role of bile and bile acids in bacterial translocation in obstructive jaundice. Eur F Surg 1993; 25: 11-9.

8 Alexander JW. Nutrition and translocation. J Parenter Enteral Nutr 1990; 14: 170-4.

9 Basista $M H$, Stauber RE, van Thiel DH, Tauxe WN, Dindzans VJ. Effect of isolated portal hypertension on Kupffer cell function. Dig Dis Sci 1994; 39: 46-50.

10 Deitch EA. The role of intestinal barrier failure and bacterial translocation in the development of systemic infection and multiple organ failure. Arch Surg 1990; 125: 403-4.

11 Vorobioff J, Bredfeldt JE, Groszman RJ. Hyperdynamic circulation in portal hypertensive rat model: a primary facto for maintainance of chronic portal hypertension. $A m$ Physiol 1983; 87: G52-7.

12 Otamiri T. Oxygen radicals, lipid peroxidation, and neutrophil infiltration after small-intestinal ischemia and reperfusion. Surgery 1989; 105: 593-9.

13 Sorell WT, Quigley EMM, Jin G, Johnson TJ, Rikkers LF. Bacterial translocation in portal-hypertensive rat: studies in basal conditions and on exposure to shock. in basal conditions and on

14 Dargl R. Lipid peroxidation - a common pathogenetic mechanism? Exp Toxicol Pathol 1992; 44: 169-81

15 Grisham MB, Hernandez LA, Granger DN. Xanthine oxidase and neutrophil infiltration in intestinal ischemia. $A m$ f Physiol 1986; 251: 9567-75.

16 Deitch EA, Bridges W, Baker J. Hemorrhagic shockinduced bacterial translocation is reduced by xanthine oxidase inhibition or inactivation. Surgery $1988 ; 104$ 191-8.

17 Wiren M, Magnusson KE, Larson J. Enteral glutamine increases growth and absorptive capacity of intestinal mucosa in the malnurished rat. Scand $¥$ Gastroenterol mucosa in the maln $1995 ; 30: 146-52$.

18 Wong SHY, Knight JA, Hopfer SM, Zaharia O, Leach CN, Sunderman FW. Lipidperoxides in plasma as measured by liquid-chromatographic separation of malondialdehyde-thiobarbituric acid adduct. Clin Chem 1987; 33: 214-20.

19 Krawisz JE, Sharon P, Stenson WF. Quantitative assay for acute intestinal inflammation based on myeloperoxidase activity: assessment of inflammation in rat and hamster models. Gastroenterology 1984; 87: 1344-50.

20 Al Amri SM, Allam AR, Al Mofleh IA. Spontaneous bacterial peritonitis and culture negative neutrocytic ascites in patients with non-alcoholic liver cirrhosis. $\mathcal{f}$ Gastroenterol patients with non-alcoholic
Hepatol 1994; 9: 433-6.

21 Llovet JM, Bartoli R. Planas R, Cabre E, Jiminez M, Urban $\mathrm{A}$, et al. Bacterial translocation in cirrhotic rats. Its role in the development of spontaneous bacterial peritonitis. Gut 1994; 35: 1648-52.

22 Sedman PC, Macfie J, Sagar P. The prevalence of gut translocation in humans. Gastroenterology 1994; 107 643-9.

23 Alexander JW, Boyce ST, Babcock GF, Gianotti L, Peck MD, Dunn DL. The process of microbial translocation. MD, Dunn DL. The process

24 Deitch EA. Bacterial translocation: the influence of dietary variables. Gut 1994; 35 (suppl 1): S23-7.

25 Blanchet L, Lebrec D. Changes in splanchnic blood flow in portal hypertensive rats. Eur $\mathcal{f}$ Clin Invest 1982; 12: 327-31.

26 Deitch EA, Winterton J, Ma L, Berg RD. The gut as a portal of entry for bacteremia. The role of protein malnutrition. Ann Surg 1987; 205: 681-92.

27 Runyon BA. Bacterial infections in patients with cirrhosis. f Hepatol 1993; 18: 271-2.

28 Cahill CJ, Pain JA, Bailey ME. Bile salts, endotoxin and renal function in obstructive jaundice. Surg Gynecol Obstet 1987; 165: 519-22.

29 Deitch EA, Ma WJ, Ma L, Berg R, Specian RD. Endotoxin induced bacterial translocation: a study of mechanisms. induced bacterial translocation:

$30 \mathrm{Ma} \mathrm{L}$, Specian RD, Berg RD, Deitch EA. Effects of protein malnutrition and endotoxin on the intestinal mucosal barrier to the translocation of indigenous flora in mice. fPEN 1989; 13: 572-8.

31 Barber AE, Jones WG, Minei JP. Bacterial overgrowth and intestinal atrophy in the etiology of gut barrier failure in the rat. Am f Surg 1991; 161: 300-4.

32 Shibayama Y, Nakata K. Hemodynamic alterations and their basis in biliary obstruction. Liver 1992; 12: 175-8.

33 Britton RS, Bacon BR. Role of free radicals in liver disease and hepatic fibrosis. Hepatogastroenterology 1994; 41: and he 8 .

34 Deitch EA, Taylor M, Grisham M, Ma L, Bridges W, Berg R. Endotoxin induces bacterial translocation and increases xanthine oxidase activity. $\mathcal{f}$ Trauma 1989; 29: 1679-83.

35 Muriel P, Suarez OR. Role of lipid peroxidation in biliary obstruction. F Appl Toxicol 1994; 14: 423-6.

36 Lemonnier F, Cresteil D, Fueant M, Couturier M, Bernard $O$, Alagille D. Plasma lipid peroxides in cholestatic children. Acta Pediatr Scand 1987; 76: 928-34.

37 Weiss SJ. Tissue destruction by neutrophils. $N$ Engl f Med 1989; 320: 365-76.

38 Deitch EA, Taylor M, Grisham M, Ma L, Bridges W, Berg R. Endotoxin induces bacterial translocation and increases xanthine oxidase activity. F Trauma 1989; 29: increases

39 Megison SM, Horton JW, Chao H, Walker BB. Prolonged survival and decreased mucosal injury after low-dose enteral allopurinol prophylaxis in mesenteric ischemia. f Pediatr Surg 1990; 25: 917-21

40 Van der Hulst RRWJ, van Kreel BK, von Meyenfeldt MF. Glutamine and the prevention of gut integrety. Lancet 1993; 341: 1363-5.

41 Barber EA, Jones WG, Minei JP. Glutamine or fiber supplementation of a defined formula diet: impact on bacterial translocation, tissue composition, and response to endotoxin. IPEN 1990; 14: 335-9.

42 Smith SD, Cardona MA, Wishnev SA, Kurchubasche AG Rowe MI. Unique characteristics of the neonatal intestinal mucosal barrier. F Pediatr Surg 1992; 27: 334-8.

43 Groot $H$ de. Reactive oxygen species in tissue injury. Hepatogastroenterology 1994; 41: 328-32. 